\title{
Investigation of the thermodynamic and physicochemical properties of lavender oil (Lavandula angustifolia Mill.)-ethanol-water system
}

\author{
Vanya Gandova ${ }^{1}$, Stanislava Tasheva ${ }^{1 *}$, Vanya Prodanova-Stefanova ${ }^{2}$, Krasimira $_{\text {Dobreva }}{ }^{2}$, \\ Ivayla Dincheva $^{3}$ and Albena Stoyanova ${ }^{1}$ \\ ${ }^{1}$ University of Food Technologies, Plovdiv, 4002, Bulgaria \\ ${ }^{2}$ Trakia University, Dept. Food Technology, Yambol, 8600, Bulgaria \\ ${ }^{3}$ PlantGeneticResearch Group, Agrobioinstitute, Agricultural Academy, 1164, Sofia, Bulgaria
}

\begin{abstract}
The thermodynamic and physicochemical properties of lavender oil (Lavandula angustifolia Mill.)-ethanol-water system were measured. The chemical composition of solutions of the lavender oil in $70 \%, 75 \%, 80 \%, 85 \%, 90 \%$, and $95 \%$ ethanol was determined using $\mathrm{GC} / \mathrm{MS}$ analysis. The main compounds in the solutions are oxygenated monoterpenes ( $\beta$-linalool, terpinen-4-ol, $\alpha$-terpineol, and linalyl acetate), followed by monoterpene hydrocarbons ((Z)- $\beta$-ocimene and (E)- $\beta$ ocimene), and sesquiterpene hydrocarbons ( $\beta$-caryophyllene and (E)- $\beta$ farnesene). The ternary phase diagrams were constructed. By multiply linear regression model for surface tension prediction was applied. The thermodynamic and kinetic parameters of lavender oil - ethanol - water system were calculated (energy of Gibb's, enthalpy, entropy, energy of activation, and coefficient of diffusion).
\end{abstract}

\section{Introduction}

Lavender essential oil is obtained by steam distillation of freshly cut, flowering tops of (Lavandula angustifolia Mill. (kind Lamiaceae). The solutions of the lavender essential oil in ethanol with concentration from $70 \%$ to $95 \%$ are used in different perfumery and pharmaceutical products. The major constituents of the oil are the oxygenated monoterpenes linalyl acetate, $\beta$-linalool, terpinen-4-ol, $\alpha$-terpineol, and lavandulol acetate [1-3]. Influence of the temperature and the pressure on the thermodynamic and thermal properties of solution of different terpenic compounds, for example $\alpha$ - and $\beta$-pinene, linalool, borneol, etc., were investigated from different authors [4-11].

The essential oil content in the inflorescence of lavender cultivated in the mid hills of Uttarakhand was investigated. The quality of lavender oil produced in India was found to be comparable to that produced in Hungary, France, China, Bulgaria, Russia, and the USA [12].

\footnotetext{
*Corresponding author: st_tasheva@abv.bg
} 
Different studies were provided for described the antibacterial properties of lavender essential oil. Besides, no data exist on its ability to activate human macrophages during the innate response against Staphylococcus aureus [13].

Lavender essential oil was used since antiquity as natural active constituents in products designed for dealing with a broad range of issues including those related to human hygiene, health and personal care, and those concerned with organic agriculture and pest management.

Lane and Mahmoud [14] report on the composition and insect repellent properties of the essential oils obtained from 12 varieties of the two most commonly cultivated lavender species (L. angustifolia and L. intermedia), grown in an experimental plot in the Okanagan Valley of British Columbia, Canada. The oil composition for three lavender oil samples was also analyzed. The results shown that the locally grown plants produce essential oils that are similar to those found in other parts of the world in terms of the overall olfactory properties, and in that they contain the same constituents found in comparable lavender oils.

The extracts obtained from lavender, which were grown in Burdur Örtülü locality, was determined using HPLC and GC-MS analysis. The anti-microbial effect of the essential oil was also investigated. The dried flowers were extracted and the essential oil was distilled from the remaining part. 31 different compounds were determined by GC-MS analysis: Linalool and linalyl acetate have the highest concentration. It was observed that the lavender essential oil could completely remove the contamination caused by the microorganisms as of the 14th day. The essential oil, can be used either directly or incorporated into the cosmetics without the necessity for any other extra preservative [15].

Lavender essential oil was approved by the European Medicines Agency as herbal medicine to relieve anxiety and stress. The capability of the oil to relieve other nervous system disorders such as neuropathic pain has never been established. Oral administration of lavender oil could represent a therapeutic approach in the management of neuropathic pain states [16].

The aim of this study is to be investigating some thermodynamic and thermal properties in the ternary lavender essential oil-ethanol-water system.

\section{Material and methods}

2.1.Material. For preparation of solutions was used distilled water, lavender essential oil was provided by Kateko Ltd, Bulgaria and $95 \%$ ethanol was provided by FILLAB, Bulgaria.

The lavender essential oil was exhibited light yellow color. The main oil has the following properties: density which is determined to $0.8623 \pm 0.0$ and a refractive index $\left(n_{D}^{20}\right)$ which is determined to $1.4635 \pm 0.0$.

\subsubsection{Solutions preparation.}

To investigate the system 18 solutions between ethanol and lavender essential oil with different quantity of water were prepared. The solutions were divided in six series according the ethanol percent. First series were started with $70 \%$ and proceed with step of $5 \%$. Last series solutions were prepared only with $95 \%$ pure ethanol. 
The prepared solutions were investigated with the ratios between lavender oil and ethanol equals to: 1:5, 1:6 and 1:7. The primary composition of the samples is presented in Table 1.

Table 1. Molar ratio lavender oil: ethanol and prime composition in percent's of 18 solutions

\begin{tabular}{|c|c|c|c|c|}
\hline $\mathrm{N}^{\mathbf{0}}$ & $\begin{array}{c}\text { Lavender } \\
\text { oil: ethanol }\end{array}$ & ethanol, \% & $\begin{array}{c}\text { Lavender oil, } \\
\%\end{array}$ & Water, \% \\
\hline 1 & $1: 5$ & 70.0 & 3.3 & 26.7 \\
\hline 2 & $1: 6$ & 70.0 & 2.5 & 27.5 \\
\hline 3 & $1: 7$ & 70.0 & 2.5 & 27.5 \\
\hline 4 & $1: 5$ & 75.0 & 2.5 & 22.5 \\
\hline 5 & $1: 6$ & 75.0 & 1.7 & 23.3 \\
\hline 6 & $1: 7$ & 75.0 & 1.7 & 23.3 \\
\hline 7 & $1: 5$ & 80.0 & 3.3 & 16.7 \\
\hline 8 & $1: 6$ & 80.0 & 3.4 & 16.6 \\
\hline 9 & $1: 7$ & 80.0 & 3.4 & 16.6 \\
\hline 10 & $1: 5$ & 85.0 & 4.2 & 10.8 \\
\hline 11 & $1: 6$ & 85.0 & 3.4 & 11.6 \\
\hline 12 & $1: 7$ & 85.0 & 3.4 & 11.6 \\
\hline 13 & $1: 5$ & 90.0 & 4.2 & 5.8 \\
\hline 14 & $1: 6$ & 90.0 & 3.4 & 6.6 \\
\hline 15 & $1: 7$ & 90.0 & 3.4 & 6.6 \\
\hline 16 & $1: 5$ & 95.0 & 5.0 & 0.0 \\
\hline 17 & $1: 6$ & 95.0 & 5.0 & 0.0 \\
\hline 18 & $1: 7$ & 95.0 & 5.0 & 0.0 \\
\hline
\end{tabular}

\subsubsection{Determination of surface tension.}

The surface tension of prepared solutions was determined using maximum bubble pressure method. This method is connected with pressure $\mathrm{P}_{\max }$ indicated as maximum pressure. In following to blow appeared a small bubble in solutions from the end of the capillary. The air bubble was flushed at a constant velocity through the capillary. Pressure was created by means of an aqueous pressure gauge. Surface tension is determined by equation (1)

$$
\gamma=\frac{\mathrm{rg}}{2}\left(\Delta H \rho_{\mathrm{o}}-r \rho\right)
$$

where: $r$ - capillary radius in $(\mathrm{m}), g$ - gravity in $\left(\mathrm{m} . \mathrm{s}^{-2}\right), \Delta H$ - maximum difference in the two gauges of the gauge, $\rho_{0}, \rho-$ density of the manometric (water) and test liquid in $\left(\mathrm{kg} . \mathrm{m}^{-3}\right)$.

\subsubsection{Determination of density in solutions.}

The density of liquids was determined by a pycnometer. A well-dried pycnometer was weighed. It is filled with the test liquid of which the density will be determined. After drying, the pycnometer is weighed with the test liquid. It is then emptied, rinsed with ethanol and filled with ethanol. Then, it is weighed again. The density is determined by the equation (2).

The density of the liquids was determined by a pycnometer according to the equation 


$$
\rho=\frac{m_{1}-m}{V}=\frac{m_{1}-m}{\frac{m_{1}-m}{\rho_{1}}}=\frac{m_{1}-m}{m_{2}-m} \rho_{1}
$$

where: $\rho$ - the density of the test liquid in $\left(\mathrm{kg} \cdot \mathrm{m}^{-3}\right), \rho_{1}$ - the density of ethanol in $\left(\mathrm{kg} \cdot \mathrm{m}^{-3}\right), m$ - mass of the pycnometer in $(\mathrm{g}), m_{l}$ - mass of the pycnometer with the test liquid in $(\mathrm{g}), m_{2}$ - mass of the pycnometer with ethanol in $(\mathrm{g})$.

\subsubsection{Determination of refractive index and molar refraction.}

Measurements of the refractive index $\left(\mathrm{n}_{\mathrm{D}}\right)$ were performed at a wavelength equal to 589.3 $\mathrm{nm}$ using an Abbe type refractometer. The measurements were used to calculated molar refraction by equation (3).

$$
R_{m}=\frac{\left(n_{D}^{2}-1\right)\left(x_{1} M_{1}+x_{2} M_{2}+x_{3} M_{3}\right)}{\left(n_{D}^{2}+2\right) \rho}
$$

where: $R m$ - molar refraction in $\left(\mathrm{m}^{3} \cdot \mathrm{mol}^{-1}\right), \rho$ - density of the test liquid in $\left(\mathrm{kg} \cdot \mathrm{m}^{-3}\right), n_{D}$ - refractive index, $x$ - mole fraction of components, $M$ - molar mass of the component in $(\mathrm{kg})$.

\subsubsection{Gas Chromatograph (GC) analysis.}

The GC analysis was provided for six samples at all ethanol concentrations in ratio 1:5, which is the highest content of essential oil. This series were contained the following ratio of lavender oil: ethanol $=1: 5$. The samples contained the largest amount of lavender oil and for this reason they were preferred as quantity of essential oil has an influence in the perfumery.

The GC analysis was performed using a GC Agilent 7890A, an HP-5 ms column (30 m x $250 \mu \mathrm{m} \times 0.25 \mu \mathrm{m}$ ), temperature: $35^{\circ} \mathrm{C} / 3 \mathrm{~min}, 5{ }^{\circ} \mathrm{C} / \mathrm{min}$ to $250{ }^{\circ} \mathrm{C}$ for $3 \mathrm{~min}$, total: 49 $\mathrm{min}$; helium as a carrier gas at $1 \mathrm{~mL} / \mathrm{min}$ constant speed, and 30:1 split ratio.

The GC/MS analysis was carried out on an Agilent 5975C mass spectrometer, using helium as a carrier gas, and the same column and temperature as in the GC analysis.

The identification of chemical compounds was done by comparison to their relative retention indexes and library data. The identified constituents were arranged in order of retention time and quantity in percentage.

\subsubsection{Linear regression model.}

The surface tension prediction was provided by using of two pressures obtained after providing experiment. Maximum bubble pressure $(\Delta \mathrm{P})$ and Laplace pressure were included in the regression model. Their determinations were calculated by the equations (4-5):

$$
\begin{aligned}
& P_{\max }=\rho g \Delta H \\
& \Delta P=P_{\max }-P_{L}
\end{aligned}
$$

where: $P_{\max }$ - maximum bubble pressure in $(\mathrm{MPa}), P_{L}$ - Laplace pressure in $(\mathrm{MPa}), g$ - gravity in $\left(\mathrm{m} \cdot \mathrm{s}^{-2}\right), \rho$-density in $\left(\mathrm{kg} \cdot \mathrm{m}^{-3}\right)$. 


\subsubsection{Thermodynamic and thermal parameters calculations.}

Some thermodynamic and thermal properties (Gibbs energy, entropy, enthalpy, thermal conductivity, thermal diffusivity and specific heat capacity) were calculated to determine the stability of the system of lavender oil-ethanol-water [17].

According to the transition state theory are determined activation thermodynamic parameters (equilibrium constant, activation free energy of Gibb's, activation enthalpy and entropy) by known equations [18-22].

Specific heat capacity, thermal conductivity and diffusivity were determined according [22-23].

The molecular diffusion coefficient was calculated according to the Wilke - Chang equation given in $[20,24]$.

\subsubsection{Statistical analysis.}

It should be noted that the experiments performed were repeated three times. The results were presented by OriginPro 7.0 software.

\section{Results and discussion}

Physicochemical properties of lavender oil (L. angustifolia)-ethanol-water system as density, surface tension and refractive index were determined experimentally. The obtained results are presented in Table 2. Density and refractive index were used to calculate molar refraction in the system.

Table 2. Density, surface tension, refractive index and molar refraction of 18 experimental solutions

\begin{tabular}{|c|c|c|c|c|}
\hline $\mathrm{N}^{\mathrm{o}}$ & $\begin{array}{c}\text { Density, } \rho, 10^{-3} \\
\text { kg.m }\end{array}$ & $\begin{array}{c}\text { Surface tension, } \\
\gamma, \mathrm{mN} \cdot \mathrm{m}^{-1}\end{array}$ & $\begin{array}{c}\text { Refractive index, } \\
n_{D}^{20}\end{array}$ & $\begin{array}{c}\text { Molar refraction, } \\
\text { Rm, } 10^{-6} \mathrm{~m}^{3} \cdot \mathrm{mol}^{-1}\end{array}$ \\
\hline 1 & $0.853 \pm 0.02$ & $18.555 \pm 0.17$ & $1.3827 \pm 0.01$ & $10.726 \pm 0.11$ \\
\hline 2 & $0.849 \pm 0.02$ & $14.885 \pm 0.13$ & $1.3800 \pm 0.01$ & $10.282 \pm 0.11$ \\
\hline 3 & $0.845 \pm 0.02$ & $13.665 \pm 0.12$ & $1.3766 \pm 0.01$ & $9.983 \pm 0.12$ \\
\hline 4 & $0.853 \pm 0.02$ & $19.780 \pm 0.18$ & $1.3820 \pm 0.01$ & $11.243 \pm 0.12$ \\
\hline 5 & $0,852 \pm 0.02$ & $14.881 \pm 0.13$ & $1.3798 \pm 0.01$ & $10.844 \pm 0.12$ \\
\hline 6 & $0.851 \pm 0.02$ & $13.658 \pm 0.12$ & $1.3760 \pm 0.01$ & $10.565 \pm 0.10$ \\
\hline 7 & $0.834 \pm 0.02$ & $18.578 \pm 0.17$ & $1.3827 \pm 0.01$ & $11.733 \pm 0.12$ \\
\hline 8 & $0.833 \pm 0.02$ & $16.130 \pm 0.15$ & $1.3810 \pm 0.01$ & $11.463 \pm 0.12$ \\
\hline 9 & $0.831 \pm 0.02$ & $14.907 \pm 0.12$ & $1.3780 \pm 0.01$ & $11.188 \pm 0.13$ \\
\hline 10 & $0.825 \pm 0.02$ & $16.139 \pm 0.15$ & $1.3820 \pm 0.01$ & $12.313 \pm 0.12$ \\
\hline 11 & $0.822 \pm 0.02$ & $14.918 \pm 0.13$ & $1.3790 \pm 0.01$ & $11.867 \pm 0.11$ \\
\hline 12 & $0.819 \pm 0.02$ & $13.697 \pm 0.12$ & $1.3771 \pm 0.01$ & $11.607 \pm 0.11$ \\
\hline 13 & $0.816 \pm 0.02$ & $19.825 \pm 0.18$ & $1.3801 \pm 0.01$ & $12.731 \pm 0.13$ \\
\hline 14 & $0.812 \pm 0.02$ & $18.605 \pm 0.17$ & $1.3791 \pm 0.01$ & $12.327 \pm 0.12$ \\
\hline 15 & $0.808 \pm 0.02$ & $16.160 \pm 0.15$ & $1.3769 \pm 0.01$ & $12.041 \pm 0.13$ \\
\hline 16 & $0.801 \pm 0.02$ & $17.884 \pm 0.16$ & $1.3808 \pm 001$ & $13.208 \pm 0.13$ \\
\hline 17 & $0.799 \pm 0.02$ & $16.171 \pm 0.15$ & $1.3786 \pm 0.01$ & $12.896 \pm 0.11$ \\
\hline 18 & $0.798 \pm 0.02$ & $14.947 \pm 0.13$ & $1.3772 \pm 0.01$ & $12.677 \pm 0.12$ \\
\hline
\end{tabular}

The presented results in Table 2 have shown that all physicochemical dimensions decreased their values when ethanol in solutions increased as quantity. Surface tension and 
refractive index for pure ethanol are: $\gamma=22.80 \mathrm{mN} \cdot \mathrm{m}^{-1}$ and $\rho=0.789 \mathrm{~kg} \cdot \mathrm{m}^{-3}[17]$. The values of refractive index presented some small variations in the last solutions prepared with $90 \%$ and $95 \%$ ethanol. The refractive index in pure ethanol is 1.3617 . In this reason probably decreasing of values of refractive index of solutions with increasing quantity of ethanol leaded to values closed of pure ethanol.

The surface tension of eighteen experimental solutions was measured. The obtained results are presented in Table 2. It was seen that with increased of quantity of ethanol in solutions, the surface tension decreases. Some of the highest surface tension values is approximately $19.825 \mathrm{mN} \cdot \mathrm{m}^{-1}$. Some low value is approximately13.697 $\mathrm{mN} \cdot \mathrm{m}^{-1}$. The obtained experimental values is in agree with surface tension in pure ethanol equal to 22.80 $\mathrm{mN} . \mathrm{m}^{-1}$ and water equal to $72.75 \mathrm{mN} \cdot \mathrm{m}^{-1}$ [25]. It's known that in perfumery and cosmetics are preferred solutions with high ethanol percent. These results presented ethanol and lavender essential oil as components as stabilized system.

The molar refraction $\mathrm{Rm}$ was calculated, too. The molar mass of lavender essential oil was determined experimentally by GC analysis. By application of equation 3, the mole fractions of three main components were calculated and used, too. The results which are shown in Table 2 for molar refraction it's obvious that all values increased with increasing of ethanol percent in solutions. In solutions with $70 \%$ ethanol the values is $9.983 .10^{6}$ $\mathrm{m}^{3} \cdot \mathrm{mol}^{-1}$ but in solutions with $95 \%$ pure ethanol is $13.208 .10^{6} \mathrm{~m}^{3} \cdot \mathrm{mol}^{-1}$. According [6] the molar refraction of mixtures exhibited values between $17-20.10^{6} \mathrm{~m}^{3} \cdot \mathrm{mol}^{-1}$. The determination of molar refraction of pure water $\left(3.88 .10^{6} \mathrm{~m}^{3} \cdot \mathrm{mol}^{-1}\right)$ and ethanol $\left(12.54 .10^{6}\right.$ $\mathrm{m}^{3} \cdot \mathrm{mol}^{-1}$ ) and a mixture of ethanol-water solutions with different concentrations [26] compared with results obtained in this work $\left(13.208 .10^{6} \mathrm{~m}^{3} \cdot \mathrm{mol}^{-1}\right)$ and good agreement was observed.

Six from all solutions were investigated with GC analysis. The experimental results for chemical compositions of lavender essential oil: ethanol $=1: 5$ are presented in Table 3 . The solutions contained the largest amount of lavender essential oil were preferred because the investigation is connected with the perfumery.

- In the solution prepared with lavender essential oil with $70 \%$ ethanol was identified 42 components representing $99.43 \%$ of the total content. Six of them were in concentrations above $1 \%$ and the rest 36 constituents were in concentrations under $1 \%$. The main components in the solution (above $2 \%$ ) were: $\beta$-linalool (48.30\%), linalyl acetate $(26.14 \%)$, terpinen-4-ol (5.40\%), and $\alpha$-terpineol (5.05\%).

- In the solution prepared with lavender essential oil with $75 \%$ ethanol was identified 42 components representing $98.98 \%$ of the total content. Eight of them were in concentrations above $1 \%$ and the rest 34 constituents were in concentrations under $1 \%$. The main components in the solution (above $2 \%$ ) were: $\beta$-linalool (54.13\%), linalyl acetate $(20.81 \%)$, terpinen-4-ol (6.24\%), and $\alpha$-terpineol (3.82\%).

- In the solution prepared with lavender essential oil with $80 \%$ ethanol was identified 42 components representing $98.39 \%$ of the total content. Six of them were in concentrations above $1 \%$ and the rest 34 constituents were in concentrations under $1 \%$. The main components in the solution (above $2 \%$ ) were: $\beta$-linalool $(51.14 \%)$, linalyl acetate $(23.80 \%)$, terpinen-4-ol (6.04\%), and $\alpha$-terpineol (3.52\%).

- In the solution prepared with lavender essential oil with $85 \%$ ethanol was identified 42 components representing $98.67 \%$ of the total content. Seven of them were in concentrations above $1 \%$ and the rest 35 constituents were in concentrations under $1 \%$. The main components in the solution (above $2 \%$ ) were: $\beta$-linalool (49.07\%), linalyl acetate $(25.00 \%)$, terpinen-4-ol (5.89\%), and $\alpha$-terpineol (3.25\%).

- In the solution prepared with lavender essential oil with $90 \%$ ethanol was identified 42 components representing $97.95 \%$ of the total content. Six of them were in concentrations above $1 \%$ and the rest 36 constituents were in concentrations under $1 \%$. The main 
components in the solution (above $2 \%$ ) were: $\beta$-linalool (46.20\%), linalyl acetate $(28.30 \%)$, terpinen-4-ol (5.73\%), and $\alpha$-terpineol (2.96\%).

- In the solution prepared with lavender essential oil with $95 \%$ ethanol was identified 42 components representing $97.37 \%$ of the total content. Seven of them were in concentrations above $1 \%$ and the rest 35 constituents were in concentrations under $1 \%$. The main components in the solution (above $2 \%$ ) were: $\beta$-linalool (38.75\%), linalyl acetate $(33.10 \%)$, terpinen-4-ol (4.92\%), lavandulol acetate $(2.40 \%)$, and $\alpha$-terpineol $(2.38 \%)$.

Table 3. Chemical composition of the six investigated samples between lavender essential oil and ethanol after GC analysis

\begin{tabular}{|c|c|c|c|c|c|c|}
\hline Name & $\begin{array}{c}70 \% \\
\text { ethanol }\end{array}$ & $\begin{array}{c}75 \% \\
\text { ethanol }\end{array}$ & $\begin{array}{c}80 \% \\
\text { ethanol }\end{array}$ & $\begin{array}{c}85 \% \\
\text { ethanol }\end{array}$ & $\begin{array}{c}90 \% \\
\text { ethanol }\end{array}$ & $\begin{array}{c}95 \% \\
\text { ethanol }\end{array}$ \\
\hline n-Hexanol & $0.08 \pm 0.0$ & $0.09 \pm 0.0$ & $0.08 \pm 0.0$ & $0.07 \pm 0.0$ & $0.06 \pm 0.0$ & $0.04 \pm 0.0$ \\
\hline$\alpha$-Pinene & $0.08 \pm 0.0$ & $0.17 \pm 0.01$ & $0.14 \pm 0.01$ & $0.12 \pm 0.01$ & $0.18 \pm 0.01$ & $0.13 \pm 0.01$ \\
\hline Camphene & $0.07 \pm 0.0$ & $0.11 \pm 0.01$ & $0.09 \pm 0.0$ & $0.07 \pm 0.0$ & $0.12 \pm 0.01$ & $0.11 \pm 0.01$ \\
\hline Sabinene & $0.08 \pm 0.0$ & $0.04 \pm 0.0$ & $0.05 \pm 0.0$ & $0.03 \pm 0.0$ & $0.04 \pm 0.0$ & $0.07 \pm 0.0$ \\
\hline$\beta$-Pinene & $0.06 \pm 0.0$ & $0.06 \pm 0.0$ & $0.05 \pm 0.0$ & $0.04 \pm 0.0$ & $0.07 \pm 0.0$ & $0.13 \pm 0.01$ \\
\hline $\begin{array}{l}\text { n-Octan-1-en- } \\
3 \text {-ol }\end{array}$ & $0.73 \pm 0.06$ & $0.86 \pm 0.07$ & $0.82 \pm 0.07$ & $0.76 \pm 0.06$ & $0.72 \pm 0.06$ & $0.55 \pm 0.05$ \\
\hline n-Octanone-3 & $0.54 \pm 0.04$ & $0.59 \pm 0.05$ & $0.57 \pm 0.05$ & $0.60 \pm 0.05$ & $0.56 \pm 0.04$ & $0.60 \pm 0.05$ \\
\hline Myrcene & $0.18 \pm 0.01$ & $0.16 \pm 0.01$ & $0.19 \pm 0.01$ & $0.22 \pm 0.01$ & $0.28 \pm 0.02$ & $0.35 \pm 0.03$ \\
\hline $\begin{array}{l}\text { n-Butyl } \\
\text { butyrate }\end{array}$ & $0.05 \pm 0.0$ & $0.04 \pm 0.0$ & $0.07 \pm 0.0$ & $0.05 \pm 0.0$ & $0.06 \pm 0.0$ & $0.08 \pm 0.0$ \\
\hline n-Octan-2-ol & $0.12 \pm 0.01$ & $0.13 \pm 0.01$ & $0.15 \pm 0.01$ & $0.11 \pm 0.01$ & $0.12 \pm 0.01$ & $0.14 \pm 0.01$ \\
\hline $\begin{array}{l}\text { n-Hexyl } \\
\text { acetate }\end{array}$ & $0.32 \pm 0.02$ & $0.30 \pm 0.02$ & $0.35 \pm 0.03$ & $0.38 \pm 0.03$ & $0.40 \pm 0.03$ & $0.43 \pm 0.03$ \\
\hline$p$-Cymene & $0.05 \pm 0.0$ & $0.07 \pm 0.0$ & $0.04 \pm 0.0$ & $0.06 \pm 0.0$ & $0.07 \pm 0.0$ & $0.16 \pm 0.01$ \\
\hline Limonene & $0.07 \pm 0.0$ & $0.07 \pm 0.0$ & $0.05 \pm 0.0$ & $0.07 \pm 0.0$ & $0.08 \pm 0.0$ & $0.17 \pm 0.01$ \\
\hline Eucalyptol & $0.55 \pm 0.04$ & $0.58 \pm 0.05$ & $0.51 \pm 0.04$ & $0.57 \pm 0.05$ & $0.59 \pm 0.05$ & $0.73 \pm 0.07$ \\
\hline $\begin{array}{l}\beta \text {-(Z)- } \\
\text { Ocimene }\end{array}$ & $0.80 \pm 0.07$ & $0.52 \pm 0.04$ & $0.69 \pm 0.05$ & $0.86 \pm 0.07$ & $0.94 \pm 0.08$ & $1.81 \pm 0.17$ \\
\hline $\begin{array}{l}\beta \text {-(E)- } \\
\text { Ocimene }\end{array}$ & $0.27 \pm 0.02$ & $0.18 \pm 0.01$ & $0.24 \pm 0.02$ & $0.30 \pm 0.02$ & $0.33 \pm 0.02$ & $0.57 \pm 0.04$ \\
\hline $\begin{array}{l}\text { cis-Linalyl } \\
\text { oxide }\end{array}$ & $0.38 \pm 0.03$ & $0.52 \pm 0.04$ & $0.41 \pm 0.03$ & $0.39 \pm 0.03$ & $0.34 \pm 0.03$ & $0.28 \pm 0.02$ \\
\hline $\begin{array}{l}\text { trans-Linalyl } \\
\text { oxide }\end{array}$ & $0.24 \pm 0.02$ & $0.32 \pm 0.02$ & $0.26 \pm 0.01$ & $0.23 \pm 0.01$ & $0.20 \pm 0.01$ & $0.17 \pm 0.01$ \\
\hline$\beta$-Linalool & $\begin{array}{c}48.30 \pm 4.5 \\
0\end{array}$ & $\begin{array}{c}54.13 \pm 5.5 \\
0\end{array}$ & $\begin{array}{c}51.14 \pm 5.0 \\
0\end{array}$ & $\begin{array}{c}49.07 \pm 4.8 \\
0\end{array}$ & $\begin{array}{c}46.20 \pm 4.5 \\
0\end{array}$ & $\begin{array}{c}38.75 \pm 3.5 \\
0\end{array}$ \\
\hline $\begin{array}{l}\text { Ethyl } \\
\text { heptanoate }\end{array}$ & $0.94 \pm 0.08$ & $0.85 \pm 0.07$ & $0.97 \pm 0.08$ & $1.08 \pm 0.09$ & $1.24 \pm 0.10$ & $1.42 \pm 0.12$ \\
\hline Heptyl acetate & $0.04 \pm 0.0$ & $0.06 \pm 0.0$ & $0.08 \pm 0.0$ & $0.06 \pm 0.0$ & $0.04 \pm 0.0$ & $0.09 \pm 0.0$ \\
\hline Camphor & $0.35 \pm 0.03$ & $0.38 \pm 0.03$ & $0.37 \pm 0.03$ & $0.35 \pm 0.03$ & $0.34 \pm 0.03$ & $0.30 \pm 0.02$ \\
\hline Lavandulol & $0.86 \pm 0.07$ & $1.05 \pm 0.09$ & $0.98 \pm 0.08$ & $0.91 \pm 0.08$ & $0.85 \pm 0.07$ & $0.66 \pm 0.05$ \\
\hline Borneol & $1.51 \pm 0.13$ & $1.83 \pm 0.17$ & $1.68 \pm 0.15$ & $1.61 \pm 0.15$ & $1.48 \pm 0.13$ & $1.17 \pm 0.10$ \\
\hline Terpinen-4-ol & $5.40 \pm 0.50$ & $6.24 \pm 0.60$ & $6.04 \pm 0.58$ & $5.89 \pm 0.55$ & $5.73 \pm 0.53$ & $4.92 \pm 0.45$ \\
\hline Cryptone & $0.68 \pm 0.05$ & $1.02 \pm 0.09$ & $0.77 \pm 0.06$ & $0.68 \pm 0.05$ & $0.59 \pm 0.04$ & $0.49 \pm 0.03$ \\
\hline $\begin{array}{l}\text { n-Butyl } \\
\text { hexanoate }\end{array}$ & $0.08 \pm 0.0$ & $0.10 \pm 0.0$ & $0.10 \pm 0.0$ & $0.21 \pm 0.02$ & $0.17 \pm 0.01$ & $0.28 \pm 0.02$ \\
\hline
\end{tabular}




\begin{tabular}{|c|c|c|c|c|c|c|}
\hline$\alpha$-Terpineol & $5.05 \pm 0.49$ & $3.82 \pm 0.37$ & $3.52 \pm 0.42$ & $3.25 \pm 0.30$ & $2.96 \pm 0.25$ & $2.38 \pm 0.25$ \\
\hline $\begin{array}{l}\text { Ethyl } \\
\text { octanoate }\end{array}$ & $0.18 \pm 0.01$ & $0.20 \pm 0.01$ & $0.20 \pm 0.01$ & $0.20 \pm 0.01$ & $0.10 \pm 0.0$ & $0.10 \pm 0.0$ \\
\hline Nerol & $0.53 \pm 0.04$ & $0.56 \pm 0.04$ & $0.60 \pm 0.05$ & $0.50 \pm 0.04$ & $0.50 \pm 0.04$ & $0.30 \pm 0.02$ \\
\hline Geraniol & $0.29 \pm 0.01$ & $0.31 \pm 0.02$ & $0.30 \pm 0.02$ & $0.20 \pm 0.01$ & $0.20 \pm 0.01$ & $0.20 \pm 0.01$ \\
\hline $\begin{array}{l}\text { Linalyl } \\
\text { acetate }\end{array}$ & $\begin{array}{c}26.14 \pm 0.2 \\
5\end{array}$ & $\begin{array}{c}20.81 \pm 0.1 \\
9\end{array}$ & $\begin{array}{c}23.80 \pm 0.2 \\
2\end{array}$ & $\begin{array}{c}25.00 \pm 0.2 \\
4\end{array}$ & $\begin{array}{c}28.30 \pm 0.2 \\
7\end{array}$ & $\begin{array}{c}33.10 \pm 0.3 \\
1\end{array}$ \\
\hline Name & $\begin{array}{c}70 \% \\
\text { ethanol }\end{array}$ & $\begin{array}{c}75 \% \\
\text { ethanol }\end{array}$ & $\begin{array}{c}80 \% \\
\text { ethanol }\end{array}$ & $\begin{array}{c}85 \% \\
\text { ethanol }\end{array}$ & $\begin{array}{c}90 \% \\
\text { ethanol }\end{array}$ & $\begin{array}{c}95 \% \\
\text { ethanol }\end{array}$ \\
\hline $\begin{array}{l}p \text {-Menth-1en- } \\
7 \text {-al }\end{array}$ & $0.16 \pm 0.01$ & $0.12 \pm 0.01$ & 0.0 & $0.10 \pm 0.0$ & 0.0 & $0.10 \pm 0.0$ \\
\hline $\begin{array}{l}\text { Lavandulol } \\
\text { acetate }\end{array}$ & $1.52 \pm 0.14$ & $1.33 \pm 0.12$ & $1.60 \pm 0.15$ & $1.80 \pm 0.17$ & $2.00 \pm 0.19$ & $2.40 \pm 0.23$ \\
\hline $\begin{array}{l}\text { Linalool } \\
\text { propanoate }\end{array}$ & $0.26 \pm 0.02$ & $0.39 \pm 0.03$ & $0.20 \pm 0.01$ & $0.20 \pm 0.01$ & $0.10 \pm 0.0$ & $0.24 \pm 0.02$ \\
\hline Neryl acetate & $0.23 \pm 0.02$ & $0.20 \pm 0.01$ & $0.20 \pm 0.01$ & $0.30 \pm 0.02$ & $0.40 \pm 0.03$ & $0.41 \pm 0.03$ \\
\hline $\begin{array}{l}\text { Geranyl } \\
\text { acetate }\end{array}$ & $0.52 \pm 0.04$ & $0.46 \pm 0.03$ & $0.56 \pm 0.04$ & $0.60 \pm 0.05$ & $0.68 \pm 0.06$ & $0.96 \pm 0.08$ \\
\hline $\begin{array}{l}\beta \text { - } \\
\text { Caryophyllen } \\
\text { e }\end{array}$ & $0.43 \pm 0.03$ & $0.25 \pm 0.02$ & $0.33 \pm 0.03$ & $0.40 \pm 0.03$ & $0.58 \pm 0.05$ & $1.52 \pm 0.14$ \\
\hline $\begin{array}{l}\beta-(Z)- \\
\text { Farnesene }\end{array}$ & $0.11 \pm 0.01$ & $0.14 \pm 0.01$ & $0.08 \pm 0.0$ & $0.10 \pm 0.0$ & $0.16 \pm 0.01$ & $0.51 \pm 0.04$ \\
\hline $\begin{array}{l}\beta \text {-(E)- } \\
\text { Farnesene }\end{array}$ & $0.14 \pm 0.01$ & $0.10 \pm 0.0$ & $0.06 \pm 0.0$ & $0.08 \pm 0.0$ & $0.09 \pm 0.0$ & $0.12 \pm 0.01$ \\
\hline $\begin{array}{l}\text { Caryophyllen } \\
\text { e oxide }\end{array}$ & $0.23 \pm 0.02$ & $0.11 \pm 0.01$ & $0.25 \pm 0.02$ & $0.30 \pm 0.02$ & $0.33 \pm 0.03$ & $0.58 \pm 0.05$ \\
\hline$\alpha$-Cadinol & $0.07 \pm 0.0$ & $0.16 \pm 0.01$ & $0.10 \pm 0.0$ & $0.13 \pm 0.01$ & $0.10 \pm 0.01$ & $0.14 \pm 0.01$ \\
\hline $\begin{array}{l}\text { oxygenated } \\
\text { hydrocarbons, } \\
\%\end{array}$ & 3.81 & 4.26 & 4.21 & 4.35 & 4.21 & 4.40 \\
\hline $\begin{array}{l}\text { monoterpene } \\
\text { hydrocarbons, } \\
\%\end{array}$ & 1.63 & 1.33 & 1.52 & 1.74 & 2.06 & 3.41 \\
\hline $\begin{array}{l}\text { oxygenated } \\
\text { monoterpenes } \\
, \%\end{array}$ & 93.52 & 93.58 & 93.41 & 92.82 & 92.38 & 89.10 \\
\hline $\begin{array}{l}\text { phenyl } \\
\text { propanoids } \%\end{array}$ & 0.05 & 0.07 & 0.04 & 0.06 & 0.07 & 0.16 \\
\hline $\begin{array}{l}\text { sesquiterpene } \\
\text { hydrocarbons, } \\
\%\end{array}$ & 0.69 & 0.49 & 0.47 & 0.59 & 0.84 & 2.19 \\
\hline $\begin{array}{l}\text { oxygenated } \\
\text { sesquiterpene, } \\
\%\end{array}$ & 0.30 & 0.27 & 0.36 & 0.44 & 0.44 & 0.74 \\
\hline
\end{tabular}


In this study, the oxygenated monoterpenes and oxygenated hydrocarbons were the dominant groups of chemical components in the solutions according the Table 3.From obtained experimental data can be seen that low composition of hydrocarbons at small ethanol concentrations is connected with their difficult solubility. With increase of ethanol concentration, the oxygen monoterpenes content decreased but hydrocarbons increased.

GC analysis of six solutions the main components were determined. In the solutions they are oxygenated monoterpenes: $\beta$-linalool, terpinen-4-ol, $\alpha$-terpineol, linalyl acetate with up to $5 \%$. The results are used to constructed experimental phase diagrams. Two phase diagrams for solutions prepared with $75 \%$ and $80 \%$ ethanol are presented in Figs. 1-2. These two solutions were preferred because the main components $\beta$-linalool and linalyl acetate exhibited highest values in these solutions. Fig. 1 presented results for the solution with $75 \%$ ethanol. The symbols denoted the point of equilibrium between each tree component (oil-ethanol-water) total compositions of each sample. In the phase diagram four primary compounds were observed: $\beta$-linalool, terpinen-4-ol, $\alpha$-terpineol, linalyl acetate and the equilibrium points they form with ethanol and water. The lines shown the tie-lines for the components connected with the equilibrium state in the system. Fig. 2 presented the same phase diagram at $80 \%$ ethanol and the components: $\beta$-linalool, terpinen4-ol, $\alpha$-terpineol, linalyl acetate and equilibrium points between these and ethanol. The lines presented again the tie-lines connected with the equilibrium state in the system.

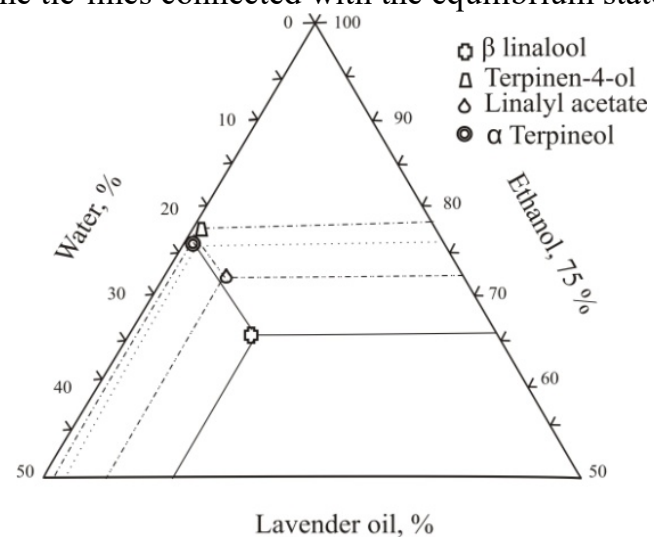

Fig. 1 Partial phase diagram for solution prepared with $75 \%$ ethanol in lavender essential oil-ethanolwater system

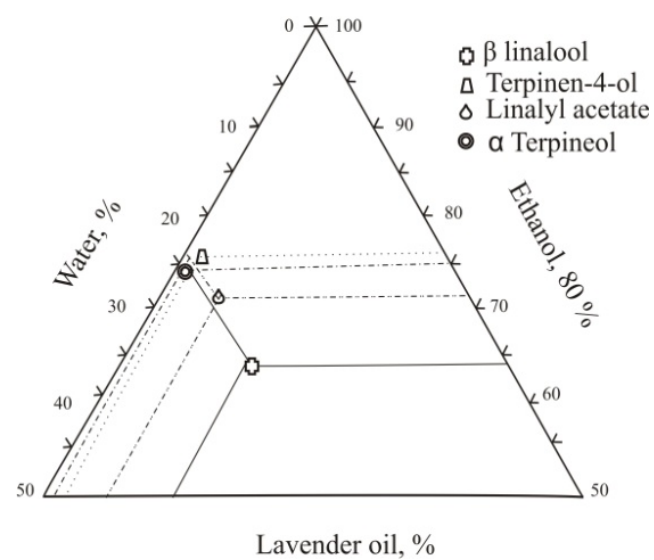

Fig. 2 Partial phase diagram for solution prepared with $80 \%$ ethanol in lavender essential oil-ethanolwater system 
Between figures 1 and 2 appeared small differences in component $\beta$-linalool. At solution prepared with $75 \%$ the component is equal to $54.13 \%$ but at solution with $80 \%$ ethanol is $51.14 \%$. With increasing of ethanol percent the $\beta$-linalool percent decreased. Opposite values for linalyl acetate increased with increasing of ethanol percent. At solution prepared with $75 \%$ is $20.81 \%$ but at solution with $80 \%$ ethanol is $23.80 \%$. These differences in chemical compositions are connected with different properties and stability of the systems, probably.

Multiple linear regression. To estimate the surface tension from two pressures, a multiple linear regresased.in model was developed [14] using the values shown in Figs. 3 and 4. Fig. 3 presented values of surface tension with dependence of density and Laplace pressure. Fig. 4 presented values of surface tension with dependence of density and maximum bubble pressure. Almost linear dependence and preferable correlation has been observed. As can be seen from the figure, there is a preferable correlation between the two tensions. According to these results two equations were obtained. In the equations " $x$ " interacts in equation (6) with a maximum bubble pressure and in equation (7) with Laplace pressure. A high coefficient of correlation $\left(\mathrm{R}^{2}=0.999\right.$ and $\left.\mathrm{R}^{2}=0.905\right)$ indicates the excellent correlations between experimental and calculation values of surface tension.
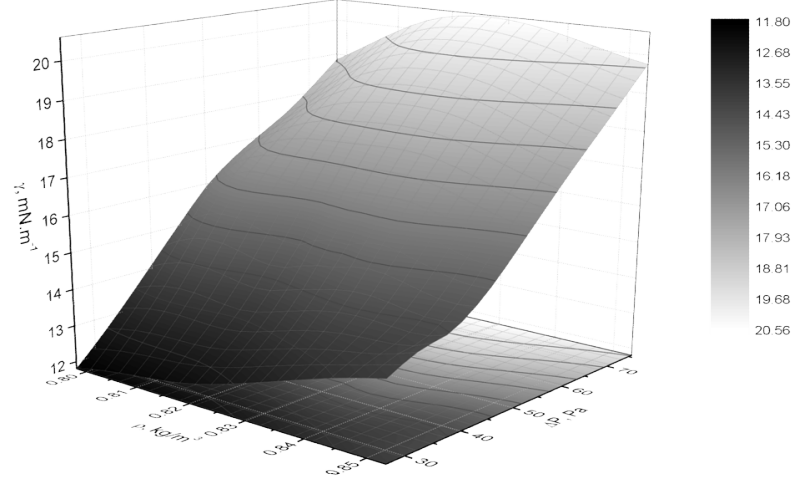

Fig. 3 Presents values of surface tension with dependence of density and Laplace pressure.

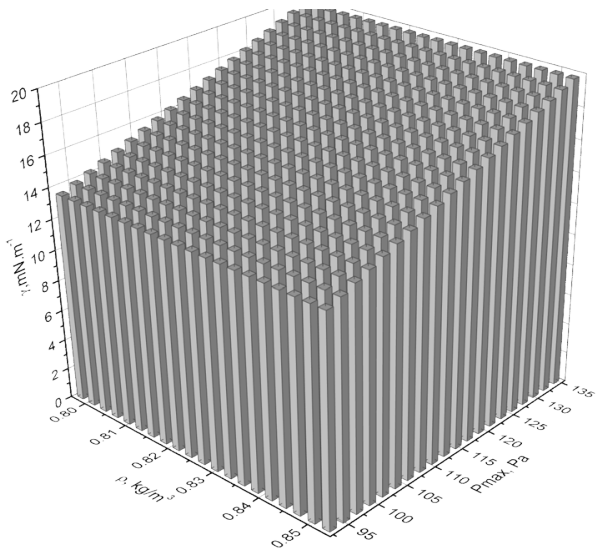

Fig. 4 Presents values of surface tension with dependence of density and maximum bubble pressure. 


$$
\begin{aligned}
& P_{\max }=-0.371+0.150 . x, R^{2}=0.999 \\
& \Delta P=9.00+0.433 . x, R^{2}=0.905
\end{aligned}
$$

To estimate the surface tension from composition of oxygenated monoterpenes, a multiple linear regression model was developed using the values showed in Table 2 and Table 3. The model is shown in equation 8. Coefficient of correlation is $\mathrm{R}^{2}=0.832$.

$$
\gamma=-211.878+5.284 . \text { L. }-19.393 . \mathrm{T}-4-\mathrm{ol}-5.284 . \mathrm{T}+\text { 3.970.La. }
$$

where: $\gamma$ - surface tencion; $\mathrm{L}$ - $\beta$-linalool; T-4-ol - terpinen-4-ol; T - $\alpha$-terpineol; La - linalyl acetate.

According to the transport theory, the values of the activating enthalpy, entropy and Gibbs energy for the transition state and for the final state of the investigated solutions of lavender oil-ethanol-water are calculated and are presented in Table 4. The value of the activating energy was calculated according to [19], which is $5726.07 \mathrm{~kJ}^{\mathrm{mol}}{ }^{-1}$. As can be seen from the presented results in the transient state, the values of the activating thermodynamic parameters are negative and decrease with increasing lavender oil: ethanol ratio of the tested solutions.

Table 4. Thermodynamic parameters of experimental lavender solutions

\begin{tabular}{|c|c|c|c|c|c|c|c|}
\hline \multirow{2}{*}{$№$} & \multirow{2}{*}{$\mathrm{K}^{\#}$} & $\Delta \mathrm{G}^{\#}$ & $\Delta \mathrm{S}^{\#}$ & $\Delta \mathrm{H}^{\#}$ & $\Delta \mathrm{G}$ & $\Delta \mathrm{S}$ & $\Delta \mathrm{H}$ \\
\cline { 3 - 8 } & & $\mathrm{kJ}_{\mathrm{mol}}{ }^{-1}$ & $\mathrm{~kJ} \cdot \mathrm{mol}^{-1} \mathrm{~K}^{-1}$ & $\mathrm{~kJ} \cdot \mathrm{mol}^{-1}$ & $\mathrm{~kJ} \cdot \mathrm{mol}^{-1}$ & $\mathrm{~kJ}^{-1} \mathrm{~mol}^{-1} \mathrm{~K}^{-1}$ & $\mathrm{~kJ}^{-m_{o}}{ }^{-1}$ \\
\hline 1 & 3.052 & -2705.956 & -9.076 & -2715.032 & -2765.837 & 9.929 & 194.398 \\
\hline 2 & 2.447 & -2169.726 & -7.277 & -2177.003 & -2217.740 & 11.767 & 1290.592 \\
\hline 3 & 2.273 & -1991.770 & -6.680 & -1998.450 & -2035.847 & 12.377 & 1654.379 \\
\hline 5 & 3.580 & -3093.215 & -10.375 & -3103.590 & -3161.666 & 8.601 & -597.259 \\
\hline 5 & 2.609 & -2326.068 & -7.802 & -2333.870 & -2377.542 & 11.231 & 970.987 \\
\hline 7 & 2.412 & -2134.816 & -7.160 & -2141.976 & -2182.058 & 11.887 & 1361.956 \\
\hline 8 & 3.588 & -3098.340 & -10.392 & -3108.732 & -3166.904 & 8.583 & -607.737 \\
\hline 9 & 2.787 & -2689.772 & -9.022 & -2698.794 & -2749.295 & 9.984 & 227.482 \\
\hline 10 & 3.255 & -2862.425 & -9.601 & -2872.026 & -2925.768 & 9.392 & -125.465 \\
\hline 11 & 2.976 & -2645.158 & -8.872 & -2654.030 & -2703.694 & 10.137 & 318.685 \\
\hline 12 & 2.722 & -2428.495 & -8.145 & -2436.640 & -2482.236 & 10.880 & 761.601 \\
\hline 13 & 4.637 & -3720.434 & -12.478 & -3732.912 & -3802.765 & 6.451 & -1879.457 \\
\hline 14 & 4.218 & -3490.448 & -11.707 & -3502.155 & -3567.690 & 7.239 & -1409.307 \\
\hline 15 & 3.490 & -3031.359 & -10.167 & -3041.527 & -3098.441 & 8.813 & -470.811 \\
\hline 16 & 4.326 & -3551.819 & -11.913 & -3563.731 & -3630.418 & 7.029 & -1534.764 \\
\hline 17 & 3.759 & -3211.219 & -10.770 & -3221.989 & -3282.281 & 8.197 & -838.490 \\
\hline 18 & 3.400 & -2967.899 & -9.954 & -2977.853 & -3033.577 & 9.031 & -341.081 \\
\hline
\end{tabular}

$\mathrm{K}^{\#}$ - equilibrium constant of the transition state; $\Delta \mathrm{G}^{\#}$ - is the activation free energy or Gibb`s energy,

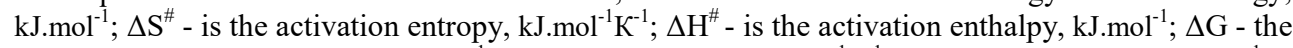

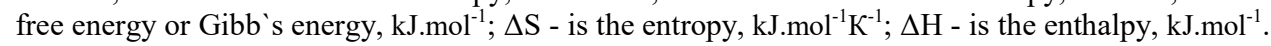

This means that in addition to the temperature as a factor influencing the thermodynamic parameters, the ratio of raw material: solvent in the studied solutions is also important. According to the obtained results, the negative values of activation entropy $\Delta \mathrm{S}^{\#}$ indicated the process was less random and non-spontaneous. The formation of activated complex due to the association mechanism is responsible for negative values of entropy. The negative values for Gibbs free energy change of the solution for ternary system specific that process was spontaneous, as shown by the values for the transient and final 
state. Which is probably due to better solubility of lavender oil in a solution with ethanol and water (better solubility of the main components of lavender oil in these solutions).

For the solutions of lavender oil-ethanol-water according to the Willie-Cheng equation, the internal molecular diffusion of the solutions at temperature $(\mathrm{T}=298.15 \mathrm{~K})$ and solvent ethanol was calculated, the value of the diffusion coefficient is $\mathrm{D}=56.27 .10^{-9} \mathrm{~m}^{2} \cdot \mathrm{s}^{-1}$.

Based on the obtained values for the final state of enthalpy, the specific heat capacity of the lavender oil-ethanol-water solutions was calculated. The coefficient of thermal conductivity is calculated, which is a thermophysical characteristic of bodies and depends on many factors, but is usually determined by empirical dependencies. Using them [27], the thermal conductivity of a solution of lavender oil-ethanol-water was calculated.

The coefficient of thermal conductivity is also calculated, representing the ratio of the coefficient of thermal conductivity related to the specific heat capacity for the studied solutions.

The higher value of $\lambda$ connected with the faster temperatures in the system equalize, or the faster given environment conducts heat. Thermal conductivity is a property of material [23]. According the experimental results the thermal properties of the system were calculated and presented in Table 5. The specific heat capacity increases with increasing ethanol concentration and with increasing lavender oil: ethanol ratio. The values for the specific heat capacity are similar to the values obtained with the linalyl acetate-ethanolwater solution presented in [22]. Due to the fact that linalyl acetate is one of the main components in lavender oil, probably. The difference between linalyl acetate and lavender solutions is based on lower values for specific heat capacity, which is probably due to the fact that lavender solutions involve the main components of lavender oil. The obtained results on the coefficient of thermal conductivity and thermal difusivity for solutions of lavender oil-ethanol-water are close to the values for solutions of linalool-ethanol-water presented in $[17,22]$, which is explained by the fact that the components involved in the solutions are oxygen-containing monoterpenes.

Table 5. Thermal parameters of lavender oils solution

\begin{tabular}{|c|c|c|c|}
\hline № & $\mathrm{c}_{\mathrm{p}}, \mathrm{kJ} \cdot \mathrm{mol}^{-1} \mathrm{~K}^{-1}$ & $\lambda 10^{3}, \mathrm{~W} \cdot \mathrm{m}^{-1} \mathrm{~K}^{-1}$ & $\mathrm{a} 10^{6}, \mathrm{~m}^{2} \cdot \mathrm{s}^{-1}$ \\
\hline 1 & 35.073 & 330.364 & 9.419 \\
\hline 2 & 33.279 & 330.366 & 9.927 \\
\hline 3 & 31.661 & 330.368 & 10.435 \\
\hline 4 & 37.985 & 330.364 & 8.697 \\
\hline 5 & 36.379 & 330.364 & 9.081 \\
\hline 6 & 34.459 & 330.365 & 9.587 \\
\hline 7 & 41.494 & 330.374 & 7.962 \\
\hline 8 & 39.012 & 330.374 & 8.468 \\
\hline 9 & 37.840 & 330.375 & 8.731 \\
\hline 10 & 44.157 & 330.379 & 7.482 \\
\hline 11 & 42.669 & 330.38 & 7.743 \\
\hline 12 & 40.658 & 330.382 & 8.126 \\
\hline 13 & 47.294 & 330.384 & 6.986 \\
\hline 14 & 45.582 & 330.386 & 7.248 \\
\hline 15 & 43.287 & 330.388 & 7.632 \\
\hline 16 & 52.635 & 330.392 & 6.277 \\
\hline 17 & 50.554 & 330.393 & 6.535 \\
\hline 18 & 48.632 & 330.393 & 6.794 \\
\hline
\end{tabular}

$\mathrm{c}_{\mathrm{p}}$ - specific heat capacity $\mathrm{kJ} \cdot \mathrm{mol}^{-1} \mathrm{~K}^{-1} ; \lambda$ - coefficient of thermal conductivity, W.m ${ }^{-1} \mathrm{~K}^{-1}$; a - coefficient of thermal difusivity, $\mathrm{m}^{2} \cdot \mathrm{s}^{-1}$. 
Three thermal parameters according calculations obtained in this work: $\lambda=0.33 \mathrm{~W} . \mathrm{m}^{-}$ ${ }^{1} \mathrm{~K}^{-1} ; \mathrm{Cp}=31.661-52.635 \mathrm{\kappa J} \cdot \mathrm{mol}^{-1} \mathrm{~K}^{-1} ; \mathrm{a}=6.277-10.435 .10^{-6} \mathrm{~m}^{2} . \mathrm{s}^{-1}$. In literature are given results for same components of essential oil linalool and linalyl acetate, and the results compared with literature data for the same parameters, obtained experimentally [17, $22,27]$.

\section{Conclusions}

Lavender oil-ethanol-water systems were investigated by different methods. Some physicochemical and thermal properties in the system were calculated. Density, surface tension and refractive index were determined experimentally. They are decreased when ethanol in solutions increased as quantity. These results presented lavender essential oil as component that stabilized system. Molar refraction of solutions was obtained with calculations. The values were between $9.98 .10^{6} \mathrm{~m}^{3} \cdot \mathrm{mol}^{-1}$ in solutions with $70 \%$ ethanol and $13.21 .10^{6} \mathrm{~m}^{3} \cdot \mathrm{mol}^{-1}$ in solutions with $95 \%$ ethanol. Two phase diagrams are presence at $75 \%$ and $80 \%$ ethanol in solutions. In the two phase diagrams four main components $\beta$-linalool, terpinen-4-ol, $\alpha$-terpineol, and linalyl acetate are presence. Three thermal parameters according calculations obtained in this work presented values: $\lambda=0.33 \mathrm{~W} \cdot \mathrm{m}^{-1} \mathrm{~K}^{-1} ; \mathrm{Cp}=$ $31.661-52.635 \mathrm{KJ} \cdot \mathrm{mol}^{-1} \mathrm{~K}^{-1} ; \mathrm{a}=6.277-10.435 .10^{-6} \mathrm{~m}^{2} . \mathrm{s}^{-1}$. The multiple linear regressions, preferable correlation between experimental surface tension values was obtained. A high coefficient of correlations was observed in three dependent and independent variables; $\mathrm{R}^{2}=$ 0.999 and $\mathrm{R}^{2}=0.905$, for pressures and $\mathrm{R}^{2}=0.832$ for chemical composition of monoterpenes.

\section{References}

1. K. Bauer, D. Garbe, H. Surburg, Common fragrance and flavor materials, Preparation, properties and uses, (fourth completely revised Edition, Weinheim, NewYork, Chichester, Brisbane, Singapore, Toronto, Wiley-VCH, 2001).

2. K.H.C. Başer, G. Buchbauer, Handbook of essential oils: science, technology, and applications, (Taylor and Francis Group, 2010).

3. E. Georgiev, A. Stoyanova, A guide for the specialistin the aromatic industry. (UFT Acad. Publ. House, Plovdiv, Bulgaria, 2006).

4. A. Arce, A. Marchiaro, A. Soto. J. Sol. Chem., 33, 561, (2004).

5. R. Clara, A. Gymez Marigliano, V. Del Campos, H. Sylimo, Fluid Phase Equilibria, 293, 151, (2010).

6. S. Garcia-Abarrio, M. Torcal, M. Haya, J. Urieta, A. Mainar, J. Chem. Therm., 43, 527, (2011).

7. S. Garcia-Abarrio, L. Viloria, L. Haya, J. Urieta, A. Mainar, Fluid Phase Equilibria, 308, 78, (2011).

8. K. Li, K. Tamura, Fluid Phase Equilibria, 263, 223, (2008).

9. V. Štejfa, M. Fulem, K. Ruzicka, C. Cervinka, J. Chem. Therm., 79, 272, (2014).

10. V. Štejfa, M. Fulem, K. Ruzicka, C. Cervinka, J. Chem.Therm., 79, 280, (2014).

11. M. Torcal, M. Teruel, J. Garc1, J. Urieta, A. Mainar, J. Chem. Eng. Data, 55, 5332, (2010).

12. R. Verma, L. Rahman, C._Chanotiya, R. Verma, A. Chauhan, A. Singh, A. Yadav, J. Serbian Chem. Soc., 75, 343, (2010). 
13. D. Giovannini, A. Gismondi, A. Basso, L. Canuti, R. Braglia, A. Canini, F. Mariani, G. Cappelli, Immunol. Invest., 45, 11, (2016).

14. W. Lane, S. Mahmoud, Nat. Prod. Commun., 3, 1361, (2008).

15. A. Turgut, F. Emen, H. Canbay, R. Demirdöğen, N. Çam, D. Kılıç, T. Yeşilkaynak, JOTCSA, 4, 283, (2017).

16. M. Sanna, F. Les, V. Lopez, N. Galeotti, Front. Pharmacol., 10, 1, (2019).

17. Tasheva, V. Gandova, K. Dobreva, I. Dincheva, V. Prodanova-Stefanova, A. Stoyanova, RJPBCS, 10, 220, (2019).

18. S. Sepida, Z. Abidin, R. Yunus, A. Muhammad, A. Amer, Jour. Applied Sci., 6, 1390, (2009).

19. H. Topallar, Ü. Geçgel, Turk. Journ. Chemical, 24, 247, (2000).

20. K. Anbalagan, M. Magesh Kumar, K. Ilango, R. Mohankumar, R. Lakshmi Pria, Ind. Crops Prod., 140, 1, (2019).

21. D. Paunovic, S. Mitic, D. Kostic, M. Mitic, B. Stojanovic, J. Pavlovic. Advanced Technologies, 3, 58, (2014).

22. V. Gandova, S. Tasheva, K. Dobreva, V. Prodanova-Stefanova, K. Marinova, A. Stoyanova, E3W Conf. $25^{\text {th }}$ Sceintific Conference on Power Engineering and Power Mashines (PEPM'2020) 204, 01022, (2020).

23. F. Incropera, D. Dewitt, T. Bergman, A. Lavine, Fundaments of heat and mass transfer, (John Wiley \&Sons, 2006).

24. S. Tasheva, V. Gandova, V. Popova, T. Ivanova, A. Stoyanova, $20207^{\text {th }}$ International Conference on Energy Efficiency and Agriculture Engineering (EE\&AE), 1, (2020).

25. R. Belda, J. Herraez, O. Diez, Phys. Chem. Liq., 43, 91, (2005).

26. J. Khan, M. Farooqui, S. Quardi, Ras. Jour. Chem., 4, 944, (2011).

27. W. Yang, S. Sokhansanj, J. Tang, P. Winter, Biosystems Engineering, 82, 169, (2002). 